free and easy. Cough and expectoration, more or less, daily continued, but at the end of every ten days or fortnight, the cavity becoming full, "half a pint"* of purulent discharge, very fœtid, both in smell and taste, was coughed up, usually preceded by a sense of fulness about the bronchiæ; the discharge, from the quantity accumulated and violence of the cough, was in part forced through the nostrils to a considerable distance. It was observed that, on the intermediate days, the expectorated fluid was much less offensive.

The foregoing symptoms, with large periodical discharges of pus, continued from May, 1814, to the 14th of May, J822, when, during a fit of coughing, the mast was ejected, having entered the larynx in the month of November, 1812, and retained nearly ten years. The figure of the mast is perfect, having a crack on one of the sides.

The physiological influence upon the constitution in this case is worthy of remark, growth and development having been arrested in their progress. At the age of sixteen not the slightest appearance of the mammæ was to be perceived; the points of the fingers and toes projected considerably beyond the extremities of the nails, presenting a very curious appearance. About a week after the mast was ejected she was able to walk the distance of scven miles without fatigue, and sang her evening hymn, which she had not been able to do since the accident, nor, as her mother assured me, could she walk the distance of a furlong without exciting violent coughing, difficulty of breathing, and a pricking sensation in her throat, with pain in both legs, whicn had become much tumefied. In the year 1821 she consulted a physician, and expressed to him her belicf that the mast was still in her throat, as, during a fit of coughing, she could feel it sliding up and down, causing a sense of soreness in the larynx, and, to use her own expressive words, she felt "as if it was coming into her mouth, and thought she could reach it with her finger." From the supposed perishable nature of such a substance, she was assured of the improbability of its existence, as at so remote a period it must have long since decayed and been expelled. He expressed an opinion that it had caused ulceration of the lungs, and gave an unfavorable prognosis. It should be remarked, however, that she remained free from any other phthisical symptoms, such as hectic fever, night sweats, or diarrhœa. A few weeks after the ejection of the mast, the periodical discharges of pus gradually began to lessen both in frequency and quantity; I saw her three months after, when a fit of coughing came on in my presence, a tablespoonful of pus being thrown up, the usual quantity then daily expectorated.

About a year and a half following the expulsion, grow th became visible, the mamma showed marks of devclopment, and in two years menstruation commenced. Four ycars after she had a scvere attack of bronchitis, when, from the large quantity of purulent expectoration, the existence of a cavity could scarcely be doubted. She was married about ten years after the expulsion of the mast, and has now four healthy children. An interval of one or two ycars has since occurred, in which both cough and expectoration

\footnotetext{
- This quantity the mother repcatedly asserted was the amount.
}

had cntirely ccased, but, on visiting her a few days since, not having seen her for several years, I found her with an infant at the breast, complaining of a return of cough and expectoration, which commenced and has continued since last Christmas, but without any other symptom than that of general debility, which may be accounted for from nursing, want of sufficient nourishment, and copious expectoration, the appearance of which confirmed my former opinion of the existence of a secreting cavity.

High Wycombe, Bucks, July 31, 1813.

\section{CASE OF TRACHEOTOMY.}

By Thomas T. Griffifh, Esq.

\section{TO THB EDITORS OF THE PROVINCIAL MEDICAL JOURNAL.}

Gentlemen,-May I beg room for the insertion in your pages of the following case, which was to have been read at the Leeds meeting.

I remain, Gentlemen, Your obedient servant,

Wrexham, Aug. 28, $1843 . \quad$ Thomas T. Griffith.

Sept. 5, 1841. John Fagan, aged five, whilst eating a small plum, suddenly fell down, apparently in a state of suffocation. On recovering, he said " the plum-stone had slipped into his throat." Previously to my seeing him, a probang had been passed and he had vomited, but nothing was seen or felt of the plumstone. Shortly after this I found him with a turgid, anxious countenance, hurried and difficult respiration, and a hard, sonorous, and frequent cough. He pointed to the trachea as the seat of distress. Inspiration was easy and regular; expiration broken and noisy, particularly so at the upper and right side of the sternum. There was no sound of obstruction in the trachea. This state of things lessened, his feelings were soothed, and, with the addition of simple remedies, he soon became calm and easy, passed a good night, and on the following day was playing in the streets. My conviction of the presence of a foreign body in the chest led to his being removed to the infirmary, where he was kept in bed, and constantly watched. On the second day severe dyspnœa came on, and in my absence he was bled with some relief, and subsequently for the same symptoms leeches were applied. A temporary suspension of distressing symptoms succeeded, and as, from repcated examinations, I believed the plum-stone to be fixed, and as he was never left alone, I awaited the result.

On the morning of the fourth day violent and distressing paroxysms of dyspnœa came on, often menacing immediate suffocation, and attended with some degree of stupor and a turgid state of the veins and a rapid pulse. The question now fairly presented itself, whether these alarming symptoms depended entirely on the presence and situation of the foreign body, and admitted of no relief but from its removal-or whether tracheotomy, in preference to all other means, did not present the best mode of relieving and sustaining the respiratory process at a moment when its fatal arrest was threatened by spasmodic closure of the glottis, or the sudden propulsion of the plum-stone into that aperture? In anticipation of this state of things, I 
had previously determined to open the trachea, and the operation was inmediately performed.

The boy being properly placed, I raised a fold of skin, and, dividing it, formed a longitudinal wound in front of the trachea, extending from the first ring to the upper part of the sternum. By thus lifting up the skin, I escaped wounding a large turgid vein, which lay in the subcutaneous tissue; and the extent of wound not only gave facility to the future steps of the operation, but allowed the blood to flow readily over the chest, instead of accumulating in front of the trachea. This organ was soon laid bare, and with but little hæmorrhage. The violent struggles and cries of the patient for a time frustrated the attempts to fix the windpipe; but when this was done and cautiously punctured by the side of my finger, I enlarged the opening upwards through three rings with Cooper's hernia knife, which for this purpose answered very well. An immediate rush of air from the chest inflated the cellular tissue around the wound, and over the neck and left side of the face. Some blood collected in the air tubes, and occasioned much distress to the little patient. He was immediately raised to the sitting posture, and I passed a large male elastic catheter into the chest, which not only secured the ingress and escape of air, but acted as a sound in searching for the foreign body, which I could not discover. The breathing now became calm and the boy quiet; the catheter was then removed, and the patient placed in a proper position in bed, where he remained constantly watched for twenty-four days. Nothing distressing occurred, and the wound gradually closed.

On the twenty-fourth day, he said he felt the plum-stone passing from the left side of his chest into the trachea. This was followed by a most violent convulsive cough, croupy breathing, hurried and obstructed circulation, and all the distress and alarm that would naturally affect a sensitive child under such circumstances. The free state of the stone, and the impending danger, urgently called for an artificial opening in the trachea, which $I$ made; and through it, after the expulsion of some mucopurulent fluid streaked with blood, the plum-stone was forced out during a fit of coughing. At once the little sufferer was relieved, and nothing of moment occurred to prevent his recovery at the end of about three weeks.

This case corresponds in its symptoms, treatment, and results, with a few others which have been recently recorded; and, collectively, they afford strong evidence in favor of tracheotomy, as our best resource in those trying cases where imminent danger and in. tense suffering demand our best-directed efforts. Though the performance of this operation cannot yet be considered the rule of practice, it is more than probable that future experience will sanction it, and prove the correctness of those pathological views which have led to its adoption. Mr. Porter, in his remarks on "the abnormal anatomy of the larynx" (vide "Cyclopædia of Anatomy"), observes-"It is probably a new observation, at all events it is one of great pathological interest, that spasm of the glottis may be produced by the presence of a foreign body lodged within the bronchia." He cites two cases illustrative of this statement, and of the practical value of tracheotomy as the surest and speediest means of relief, though the expulsion of the forcign body was delayed some weeks. About the same time, Mr. B. Travers published in the twenty-third volume of the "Medico-Chirurgical Transactions," a very interesting case, treated upon the same principles with success; and, in his concluding remarks, observes-" In section of the air tube, the escape of the foreign body appears to me to be a calculation secondary in importance to that of affording a prompt and effectual relief to the process of respiration. It is evident that the powers of life depend on this issue, and that these may be secured for a time by an artificial opening, although the source of irritation be still present."

\section{CASES OF DIABETES.}

By Charles F. Favel., M.D.,

Physician to the Sheffield General Infirmary, \&c.

The following brief account of three cases of diabetes is curtailed from the much more extensive notes of my case-book. It appears to me that each possesses a peculiar interest-the first from the post-mortem examination which I succeeded in obtaining, the second from the effect of treatment, and the third from the mode of death.

Case I.-William Mallander, aged twenty-eight, a sickle smith, was admitted into the Sheffield Infirmary under my care on April 19, 1839. He is a married man, and has two children. According to his own account he always enjoyed good health till the commencement of his present illness, and has been very sober in his habits. He is accustomed to work near a very hot fire, which has generally occasioned profuse perspiration, and, whilst perspiring freely, he has been in the habit of exposing himself to the cold outer air. About six months since he was seized with pain in the stomach and bowels, which continued for a long time and was accompanied with excessive thirst, so that, he says, he sometimes drank more than six gallons of cold water'during the night. During this time he passed a very large quantity of urine in the twenty-four hours. At present he is much reduced in flesh and strength; the appetite voracious; says he is always hungry, but experiences pain and uneasiness at the stomach after taking food; great thirst; mouth dry and parched; tongue clean, but very red; taste impaired; skin dry and constricted; never perspires, but complains of burning of the palms of the hands and soles of the feet; for some weeks has passed from four to five gallons of urine in the twentyfour hours. Urine of a pale straw color, having a smell resembling new hay, and a taste like honey; specific gravity 1.040 ; on evaporation, it yields a large proportion of solid extract, which has the smell and taste of burnt sugar. Bowels open; motions natural; pulse 90 , small, and feeble; says he has never had any pain or uneasiness in his back, but complains of a sense of numbness in the inferior extremities. He was put on an exclusively animal diet; was ordered to be cupped over the region of the kid. neys; to have a bath, at the temperature of $100^{\circ}$, every night; and to take the following medicines:-

Infusion of quassia, eight ounces ;

Tincture of opium, three drachms. Mix. To take one ounce three times a-day. 